\title{
Pioneering the Hydropower Development
}

\author{
Janak Lal Karmacharya
}

Abstract. The Clean Energy Development Bank (CEDB) has done a pioneering work to provide the loan for hydro projects without collateral under the "project financing" concept. However, a rigorous project processing regime is required to protect from any risk along with strong and continuous monitoring by the Bank. This paper highlights the requirement of technical due diligence of candidate hydro projects looking for financing. CEDB has developed and adopted a systematic hydropower project processing process Operational Policy and Guidelines. Cost-over run or time overrun due to any reason is the two major concerns for Financier as well as Developer. Rigorous screening is needed to ensure virtual risk proof lending.

With the twin objectives of, but particularly focused on financing and helping mobilize financial resources for developing hydropower projects, the Clean Energy Development Bank (CEDB) designed itself to fly by mustering banking experts from the very beginning. However it had to create an organization equipped with the proper manpower and technical documentations to make the Bank capable of conducting technical due diligence of candidate projects for financing.

The CEDB began with the development of guidelines and technique for conducting due diligence of hydropower projects intending to finance, which included identification of fatal flaws in a project design (if any), to deal with it in the early stage of the project appraisal, field visit by Bank's expert to ensure that the designed structures fit into the natural setting, and that the design parameters have been derived from a reliable natural data base and preliminary appraisal. The results must ensure the feasibility of components and the overall viability of the project and that the due diligence report be professionally acceptable.

Such rigorous screening procedures are needed to ensure virtual risk proof implementation of a hydropower project. The hydropower development is a capital intensive investment and the construction takes place in and against the nature. Careful analysis based on deep experience is necessary to ensure the least risky solution.

In view of this requirement, the CEDB has developed and adopted an Operational Policy and Guidelines, which is a sound documentation leading to an institutionalized approach to hydropower financing.

Project processing starts with preliminary appraisal which involves preliminary technical appraisal to rule out any "fatal flaw" that might occur (which may not allow proceeding with the project or suggesting early remedy out of the flaw), preliminary environmental appraisal, preliminary commercial appraisal, and preliminary financial appraisal. A field visit by the Bank's expert is launched to conduct physical assessment of site particularly the project lay- out, physical positioning of major structures, access and location of power evacuation facilities and general assessment of hydrology, sedimentology and topography. A preliminary appraisal report is produced advising the Bank management to go ahead with the financing of the project as designed by the developer or to take due consideration to suggestions by the CEDB team during field visit and preliminary appraisal. The next step is to carry out due- diligence. This involves the detailed review of hydrological geological parameters of the project adopted for design, adequacy of design, detailed cost estimate, logical construction schedule, environmental mitigation plan and mitigation measures and mechanism for mitigation of adverse impacts. In- depth financial analysis with sensitivity analysis is reviewed for its adequacy.

A critical part of the due-diligence is the risk analysis. Cost- over run or time overrun due to any reason is the two major concerns for Financier as well as Developer. The possibility and the financial implication of such over runs are to be assessed and the possible impact on the viability of the project is ascertained. The resulting financial parameters must be acceptable to the Bank.

One of the major bottleneck in the development of hydropower has been perceived to be the difficulty faced by developers in raising the collateral required to raise the loan. To address this problem, the Bank has decided to provide the loan without collateral under the "project financing concept". A rigorous project processing regime is required, however, to protect from any risk and this should be accompanied by strong and continuous monitoring by the Bank during construction, operation and maintenance of the hydropower plant till the repayment period. The Bank must have a say in the type of tendering and in the choice of the contractors and the consultants during supervision. The joint team of Financier and Developer alone can ensure the cost effective and timely delivery of the product. 
The Clean Energy Development Bank has started its journey first with strengthening of this capacity and introducing the concept of project financing. The CEDB has already created a strong ripple in the hydro market within a period of just one and half years. The CEDB is processing five hydropower projects of various capacities with the intention of financial closure.

The project financing is not an easy and risk free path. But it is the CEDB's conviction that project financing is the answer to the sluggish development of hydropower specially the small hydropower development.

Janak Lal Karmacharya, holds a PhD degree in hydrology and hydraulics, and has been working in the power sector, especially in hydropower development, for more than three and half decades. Dr. Karmacharya has participated and led studies, design and construction of hydropower schemes and development of hydropower policy in Nepal and abroad. He is a past Managing Director of the Nepal Electricity Authority, and is currently Head/Hydro Business, Clean Energy Development Bank, a member of the Steering Committee of the Dams and Development Project under UNEP, and Vice President of the International Hydropower Association. He has also served as a consultant to the World Bank and the USA-funded South Asia Regional Initiative/Energy Program.

Corresponding Address: janak.karmacharya@gmail.com 